Article

\title{
Replication of Crohn's Disease Mucosal E. coli Isolates inside Macrophages Correlates with Resistance to Superoxide and Is Dependent on Macrophage NF-kappa B Activation
}

\author{
Ahmed Tawfik ${ }^{1,2}$, Paul Knight ${ }^{1,3}$, Carrie A. Duckworth ${ }^{1}$, D. Mark Pritchard ${ }^{1}$, \\ Jonathan M. Rhodes ${ }^{1}$ and Barry J. Campbell ${ }^{1, *(D)}$ \\ 1 Gastroenterology Research Unit, Department of Cellular \& Molecular Physiology, Institute of Translational \\ Medicine, University of Liverpool, Liverpool L69 3GE, UK; ahmedtawfik13@yahoo.com (A.T.); \\ paul.knight@mft.nhs.uk (P.K.); carried@liv.ac.uk (C.A.D.); dmpritch@liv.ac.uk (D.M.P.); \\ rhodesjm@liv.ac.uk (J.M.R.) \\ 2 Gastroenterology Department, Beaumont Hospital, Dublin 9, Ireland \\ 3 Gastroenterology Department, University Hospital of South Manchester, Wythenshawe M23 9LT, UK \\ * Correspondence: bjcampbl@liv.ac.uk; Tel.: +44-151-794-6829
}

Received: 29 March 2019; Accepted: 6 June 2019; Published: 8 June 2019

check for updates

\begin{abstract}
Mucosa-associated Escherichia coli are increased in Crohn's disease (CD) and colorectal cancer (CRC). CD isolates replicate within macrophages but the specificity of this effect for $C D$ and its mechanism are unclear. Gentamicin exclusion assay was used to assess E. coli replication within J774.A1 murine macrophages. E. coli growth was assessed following acid, low-nutrient, nitrosative, oxidative and superoxide stress, mimicking the phagolysosome. Twelve of $16 \mathrm{CD}$ E. coli isolates replicated $>2$-fold within J774.A1 macrophages; likewise for isolates from 6/7 urinary tract infection (UTI), 8/9 from healthy subjects, compared with 2/6 ulcerative colitis, 2/7 colorectal cancer and 0/3 laboratory strains. CD mucosal E. coli were tolerant of acidic, low-nutrient, nitrosative and oxidative stress. Replication within macrophages correlated strongly with tolerance to superoxide stress (rho $=0.44, p=0.0009$ ). Exemplar CD E. coli HM605 and LF82 were unable to survive within $\mathrm{Nf}_{\mathrm{k}} b 1^{-1}$ murine bone marrow-derived macrophages. In keeping with this, pre-incubation of macrophages with hydrocortisone $(0.6 \mu \mathrm{M}$ for $24 \mathrm{~h})$ caused $70.49 \pm 12.11 \%$ inhibition of intra-macrophage replication. Thus, CD mucosal E. coli commonly replicate inside macrophages, but so do some UTI and healthy subject strains. Replication correlates with resistance to superoxide and is highly dependent on macrophage NF- $\mathrm{kB}$ signalling. This may therefore be a good therapeutic target.
\end{abstract}

Keywords: Escherichia coli; Crohn's disease; macrophage; phagolysosome; superoxide; hydrocortisone; Nuclear factor kappa B

\section{Introduction}

Mucosa-associated E. coli have been found in increased numbers on the ileal and colonic mucosae, including the inner adherent mucus layer, of patients with Crohn's disease (CD) [1-6] or colorectal cancer (CRC) [3-7], and to a lesser extent, patients with ulcerative colitis (UC) [8,9]. A high proportion of CD mucosal E. coli strains adhere to, and invade, intestinal epithelial cell-lines Caco-2 and Int-407, and induce release of pro-inflammatory cytokines [2-6,10]; however, it has been noted that the level of invasion into epithelial cell lines is strongly dependent on the cell line chosen for experimental study [3]. In vitro studies using the paradigm CD E. coli strains from the ileum (LF82) [1] and from the colon (HM605) [3] showed that they also possess the ability to replicate within murine and human 
monocyte-derived macrophages (HMDM) [11-14] and to induce granuloma formation, a hallmark of Crohn's disease [15]. Electron microscopy confirmed replication of CD strains LF82 and HM605 inside phagolysosomes within macrophages [11-14] and this replication was shown to favour the presence of an acidic environment [12].

Macrophages play a key role in the host's immunological and inflammatory response [16]. Activated macrophages are classified into classically activated macrophages $\left(\mathrm{M}_{1}\right.$-macrophages), which are immune effectors against pathogenic bacteria and associated with marked production of lymphokines, and alternatively activated macrophages ( $\mathrm{M}_{2}$-macrophages) having a variety of functions, including immune regulation, tissue repair and wound healing [16,17]. Genome-wide association studies (GWAS) have now identified more than 200 IBD-associated loci $[18,19]$. In CD, particularly, these include gene polymorphisms relating to innate immune system functions such as pathogen recognition (nucleotide-binding oligomerisation domain-containing-2/Caspase-recruitment domain 15 (NOD2/CARD15) and interleukin 23 receptor (IL23R)) and autophagy (immunity-related GTPase M (IRGM) and autophagy-related 16-like 1 (ATG16L1)), which are highly relevant to killing of bacteria within macrophages [19].

In vivo studies in $C D$ patients demonstrated a defect in neutrophil recruitment along with an abnormal production of cytokines following either acute trauma to the rectum or subcutaneous injection of heat-killed E. coli [20-22]. However, ex vivo studies reported normal chemotaxis of CD neutrophils $[23,24]$. We have previously reported no significant differences in killing of CD mucosal E. coli HM605, E. coli K-12 and Staphylococcus aureus Oxford strain between CD and healthy control peripheral blood monocyte-derived macrophages; moreover, active CD macrophages also showed an equivalent ability to induce neutrophil chemotaxis in vitro relative to unaffected controls [25]. No consistent abnormality in phagocytosis and respiratory burst function of MDM obtained from CD patients has been described to date [26].

Bacteria phagocytosed by macrophages are surrounded by a double membrane to form internal vesicles termed phagosomes. These phagosomes fuse with lysosomes to form mature phagolysosomes, in which their contents are degraded by reactive oxygen species (ROS) and proteolytic enzymes [27,28]. ROS are chemically reactive molecules containing free oxygen radicals, including superoxide anions $\left(\mathrm{O}_{2}{ }^{-}\right)$, hydrogen peroxide $\left(\mathrm{H}_{2} \mathrm{O}_{2}\right)$, and hydroxyl radicals $\left(\mathrm{OH}^{-}\right)$produced within the intracellular compartment under aerobic conditions through the activation of multicomponent NADPH oxidase. ROS are cytotoxic and are essential in the microbicidal process of macrophages [29,30]. CD mucosal E. coli strains, during the later phase of murine macrophage infection, induce chronic activation of NF- $\mathrm{kB}$, which correlates with increased tumour necrosis factor (TNF) secretion [31]. CD mucosal E. coli replication within macrophages has been reported to be dependent on TNF secretion [11,32].

The combination of adherence to, and invasion of, epithelial cell lines plus the ability to replicate within macrophages led to the phenotypic designation of CD mucosa-associated E. coli as Adherent, Invasive E. coli (AIEC) [10]. However, no genotype has been defined for AIEC [33], although $\mathrm{CD}$ isolates (and CRC isolates) more commonly possess key virulence genes that drive common phenotypic/pathogenic actions, including epithelial cell adherence and invasion, entry via microfold (M) cells of the follicle-associated epithelium, enhanced angiogenic potential and genotoxicity [34-38]. They are possibly best defined as pathobionts_organisms with the potential for causing disease that likely live as symbionts under circumstances of normal gut health.

Here we compare the replication within macrophages of CD, UC and CRC mucosally associated E. coli strains, E. coli strains from patients with urinary tract infection (UTI), E. coli strains from healthy individuals with no evidence of intestinal inflammation, and laboratory E. coli strains. We have also assessed their tolerance of stress conditions characteristic of the macrophage phagolysosomes and the role of the classical NF- $\mathrm{kB}$ pathway activation in this process. 


\section{Results}

2.1. Ability to Survive and Replicate within Macrophages Is Not Confined Specifically to CD Mucosal E. coli Strains

CD mucosal E. coli strains more commonly showed an ability to replicate within J774-A1 murine macrophages with 12 out of $16 \mathrm{CD}$ strains examined showing $>2$-fold replication (Figure 1); $p=0.036$ versus $0 / 3$ laboratory E. coli studied; two-sided Fisher's exact test. Mean fold replication for all isolates across the $C D$ group $( \pm S D)$ was significantly higher at 4.01 -fold $( \pm 2.60)$ versus laboratory $E$. coli studied [0.82-fold $( \pm 0.29)$ ]; $(N=3-9$ experiments, $n=3$ replicates; $p<0.01$, ANOVA). The paradigm ileal CD AIEC LF82, and the colonic CD AIEC HM605, both showed significant intra-macrophage replication $(\mathrm{LF} 82,4.67 \pm 0.73$-fold $(N=9, n=3)$ and HM605 $10.18 \pm 1.82$-fold $(N=6, n=3)$; both $p<0.001)$ compared to non-pathogenic E. coli EPI300 ( $0.67 \pm 0.11$-fold; $N=9, n=3$ ). Only 2/6 UC strains (HM233 and HM457) and 2/7 CRC strains (HM229 and HM374) were seen to replicate to a level $>2$-fold at $6 \mathrm{~h} / 3 \mathrm{~h}$ (Figure 1). Overall mean fold intra-macrophage replication the group of $E$. coli isolates tested from UC and CRC patients were $1.48 \pm 1.37$-fold and $1.46 \pm 1.24$-fold replication, respectively. Of note, significant replication within macrophages was also observed for some non-CD isolates (see Figure 1). This included 6/7 E. coli strains obtained from patients with urinary tract infection (UTI), $p=0.03$ (Fishers exact test); with mean fold replication overall being 3.76-fold $( \pm 2.13)$ higher across all UTI isolates tested, $p=0.0098$ ANOVA compared to laboratory E. coli studied. Significant survival and replication was seen for two particular UTI isolates, one from a patient with acute cystitis, ECOR64 (7.15 \pm 1.24 -fold; $p<0.001$, ANOVA; $N=3, n=3$ ) and the second the uropathogenic E. coli (UPEC) J96 (6.30 \pm 1.70 -fold; $p<0.001$ ), with all other UTI-associated E. coli showing some trend for intra-macrophage replication bar ECOR48, $1.59 \pm 0.52$-fold compared to laboratory strain EPI300. Interestingly, eight out of nine E. coli strains obtained from colonic mucosal samples from healthy individuals (i.e., with no evidence of intestinal inflammation) also showed significant replication; this included all colonic mucosa-associated HM strains tested, ECOR35 (a group D strain) and ECOR1 (a group A strain) from healthy individuals, the latter replicating significantly at $5.62 \pm 1.28$-fold within J774.A1 macrophages $(p<0.01$, ANOVA) compared with laboratory strain EPI300.

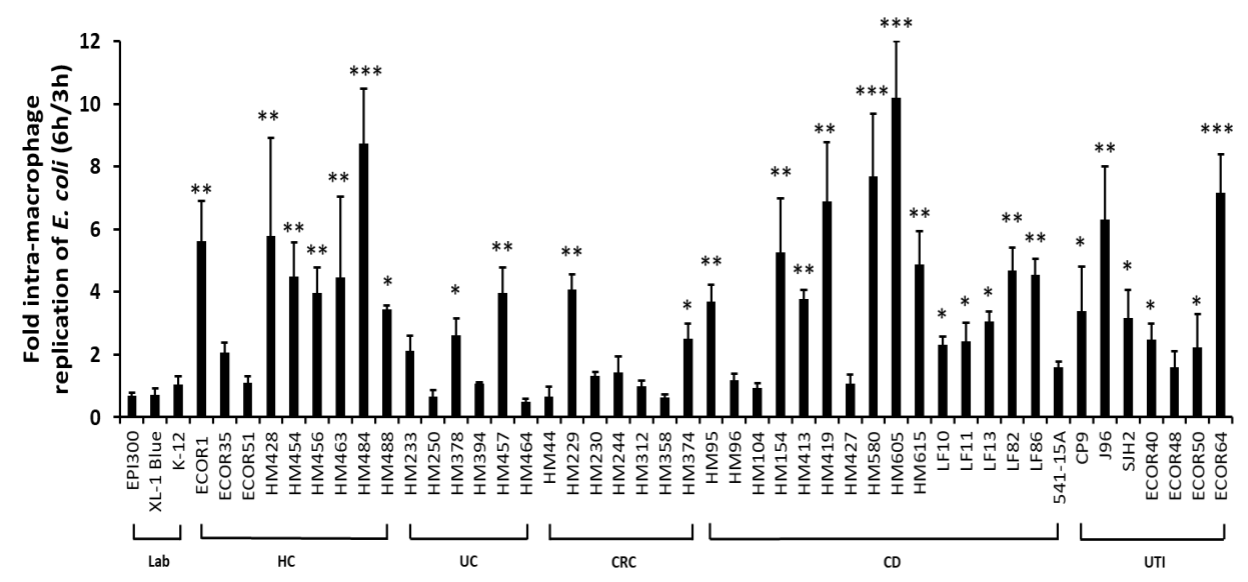

Figure 1. Crohn's disease mucosa-associated E. coli isolates show significant intra-macrophage replication. Replication of $48 \mathrm{E}$. coli $(n=16 \mathrm{CD}, n=7 \mathrm{CRC}, n=6 \mathrm{UC}, n=9 \mathrm{HC}, n=7 \mathrm{UTI}$ and $n$ $=3$ laboratory strains) was assessed by overnight bacterial culture of J774.A1 murine macrophage cell lysates following a gentamicin protection assay. Data are expressed as fold change [mean \pm $\mathrm{SD}$ ] of recovered intra-macrophage bacteria $6 \mathrm{~h}$ post-infection compared to the number of viable colony-forming units ( $\mathrm{cfu}$ ) obtained immediately after a 1-h gentamicin treatment step (i.e., $3 \mathrm{~h}$ post-infection). $N=3$ independent experiments, $n=3$ replicates, excepting for $E$. coli LF82 and EPI300 $(N=9, n=3)$, and HM605 $(N=6, n=3)$. Significant differences are indicated as follows: ${ }^{*} p<0.05$, ${ }^{* *} p<0.01$ and ${ }^{* *} p<0.001$; ANOVA with Dunnett's post hoc test compared to control (non-replicating laboratory E. coli EPI300). 
2.2. Crohn's Disease Mucosa-Associated E. coli Strains Show Ability to Tolerate Stress Conditions that Mimic the Phagolysosome Environment, in Particular Superoxide Stress

The growth of adherent, invasive CD E. coli strains LF82 and HM605 was not influenced by any of the chemical stress conditions of low $\mathrm{pH}$, high nitrosative, oxidative and high oxidative stress, with no differences in level of growth compared with that seen on reference LB agar, $\mathrm{pH} 7.0 ; N=4, n=3$ (Figure 2). A similar pattern of stress tolerance was also observed for four other CD mucosa-associated E. coli isolates of the 16 tested; LF86, HM413, HM427 and HM615 (see Figures 2 and 3). Of note too, E. coli K-12 also tolerated all stress challenge conditions (Figure 2). However, the growth of the two laboratory E. coli strains, EPI300 and XL-1Blue, both incapable of survival and replication within macrophages, was significantly suppressed under all stress conditions tested, particularly with superoxide stress (all $p<0.05$, ANOVA; $N=4, n=3$ ). CRC mucosa-associated E. coli strain HM358 was seen to tolerate growth on LB agar at $\mathrm{pH} 5.0$, under nitrosative stress and $\mathrm{H}_{2} \mathrm{O}_{2}$-mediated oxidative stress growth conditions but not in an environment of superoxide stress induced by $1 \mathrm{mM}$ methyl viologen (Figure 2).
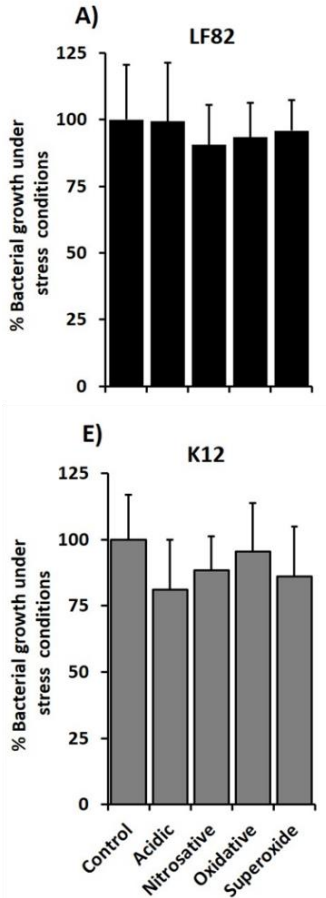

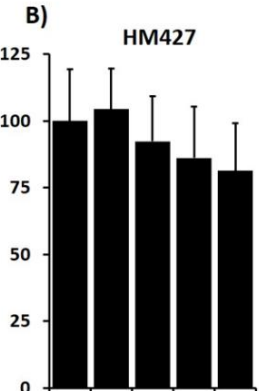

F)

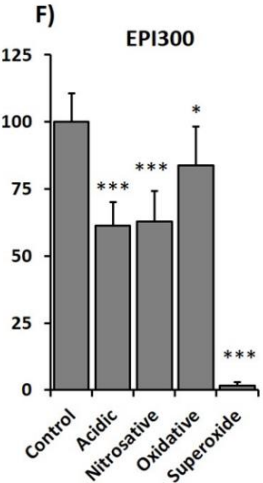

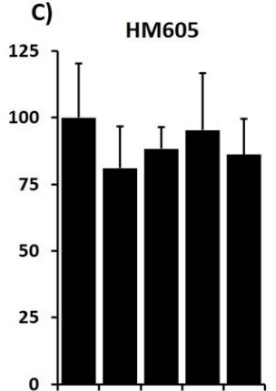

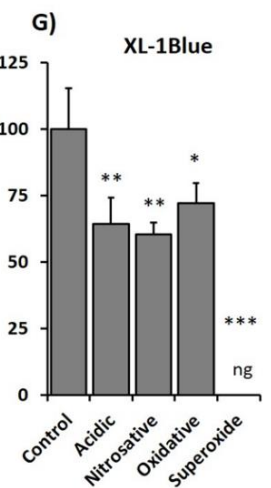

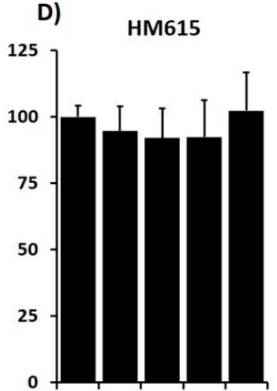

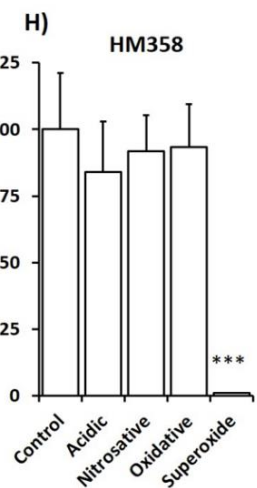

Figure 2. Mucosa-associated E. coli strains all tolerate acidic, nitrosative and oxidative stress but vary considerably in their ability to tolerate superoxide stress that mimics the phagolysosome environment. CD mucosa-associated E. coli strains LF82 (A), HM427 (B), HM605 (C) and HM615 (D) (black bars) showed significant ability to tolerate acidic stress (LB agar containing $100 \mathrm{mM}$ morpholine ethanesulphonic acid [MES], pH 5.0), nitrosative stress (LB agar containing $100 \mathrm{mM} \mathrm{MES} \mathrm{pH} 5.0$ and $1 \mathrm{mM} \mathrm{NaNO}_{2}$ ), oxidative stress ( $\mathrm{LB}$ agar containing $1 \mathrm{mM} \mathrm{H}_{2} \mathrm{O}_{2}, \mathrm{pH} 7.0$ ) and superoxide stress (LB agar containing $1 \mathrm{mM}$ methyl viologen, $\mathrm{pH}$ 7.0), compared to growth on reference LB agar pH 7.0. E. coli K-12 (E), was also tolerant to all stress conditions. Conversely, laboratory E. coli strains EPI300 (F) and XL-1Blue (G) (grey bars) were intolerant to all studied stress conditions, especially superoxide stress (ng = no growth), and colorectal cancer (CRC) E. coli strain HM358 (H) (white bars) was intolerant only to superoxide stress. Significant differences from growth on LB agar $\mathrm{pH} 7.0 ;{ }^{*} p<0.05,{ }^{* *} p<0.01$, ${ }^{* * *} p<0.001$, ANOVA with Dunnett's post hoc test ( $N=4$ experiments, $n=3$ replicates). 

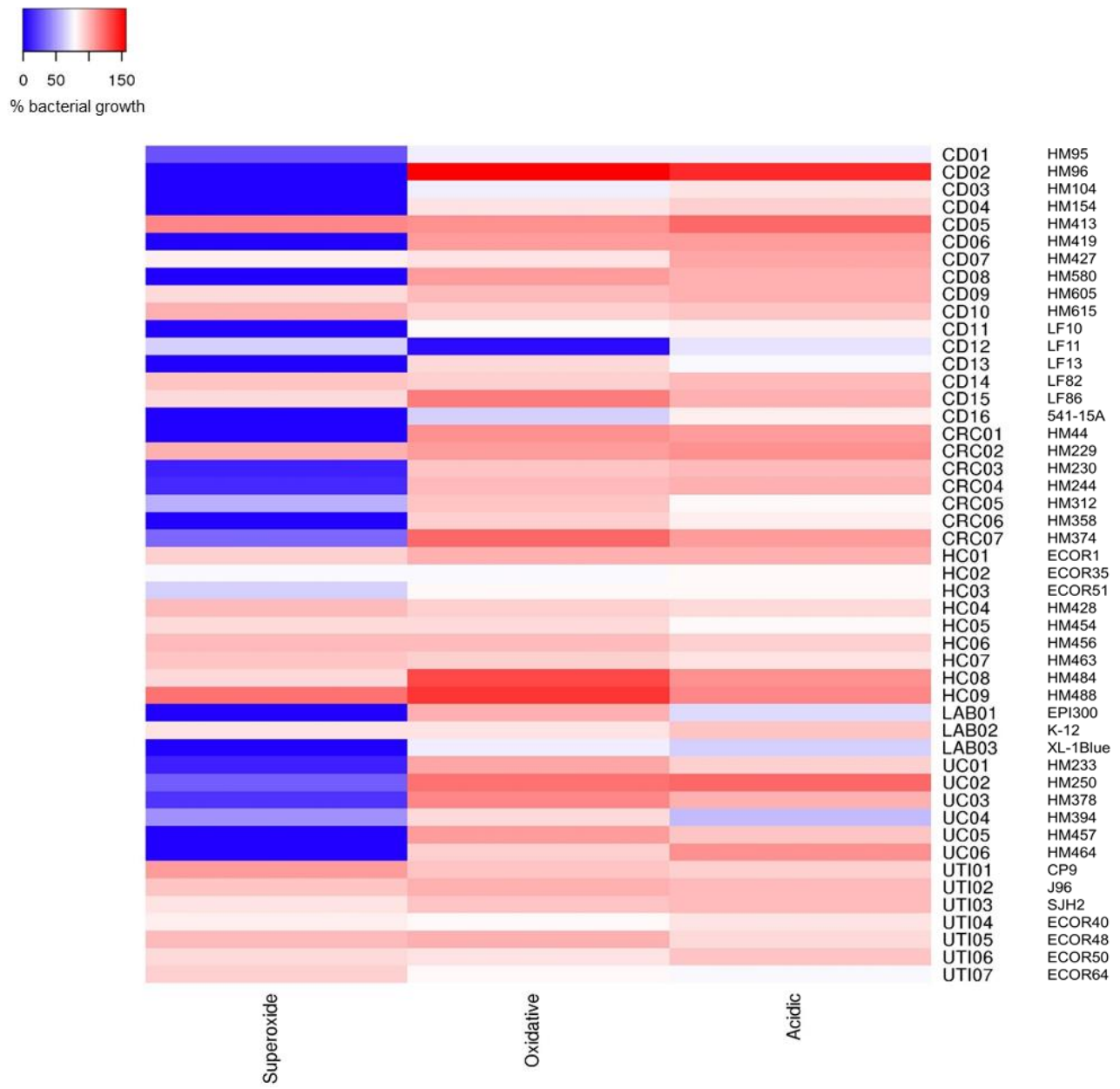

Figure 3. Stress tolerance heatmap of E. coli growth on solid media under conditions that mimic the phagolysosome environment. Data expressed as mean \% bacterial growth under stress conditions (blue $=$ intolerant, red $=$ high tolerance) compared to growth on reference LB agar $\mathrm{pH} 7.0(100 \%) ; N=4$ experiments, $n=3$ replicates. Acidic stress (LB agar containing $100 \mathrm{mM}$ morpholine ethanesulphonic acid [MES] pH 5.0); oxidative stress (LB agar containing $1 \mathrm{mM} \mathrm{H}_{2} \mathrm{O}_{2} \mathrm{pH}$ 7.0); and superoxide stress (LB agar containing $1 \mathrm{mM}$ methyl viologen $\mathrm{pH}$ 7.0). CD, Crohn's disease; CRC, colorectal cancer; UC, ulcerative colitis; UTI, urinary tract infection; HC, healthy controls; LAB, Laboratory strains.

Further examination of E. coli growth tolerance to acid, oxidative and, in particular, superoxide stress, was undertaken using additional strains obtained from healthy individuals and various patient groups. Those isolates showing $>2$-fold intra-macrophage survival within these groups were commonly found to be tolerant of acid, oxidative and superoxide stress. This was the case for all six UTI strains with $>2$-fold intra-macrophage replication, where the $\%$ mean growth was $78-99 \%$ in acidic conditions, 81-103\% in $\mathrm{H}_{2} \mathrm{O}_{2}$, induced oxidative stress and $84-107 \%$ in superoxide stress. Even the sole UTI isolate showing $<2$-fold replication, ECOR48, was tolerant to all three growth stress conditions (see Figure 3). Eight of nine isolates from healthy subject controls (i.e., without bowel inflammation) showing $>2$-fold intra-macrophage survival, also showed significant tolerance to all three stress conditions; this included irritable bowel syndrome patient isolates (HM484 and HM488), and isolates from patients with sporadic polyps (HM428, HM454, HM456) or haemorrhoids (HM463). The two intra-macrophage replicating UC strains (HM233 and HM457) were only observed to be growth tolerant to acidic and oxidative stress. Of the two CRC strains seen to replicate $>2$-fold, only HM229 was tolerant to all three stress conditions, whereas HM374 could not tolerate superoxide stress (see Figure 3).

Overall, significant tolerance to superoxide stress was observed between $E$. coli from different sources ( $p=0.0039$; Kruskal-Wallis ANOVA; $N=4$ experiments, $n=3$ replicates), particularly 
UTI-associated E. coli (7/7), strains from CD patients (6/16) and healthy controls (7/9) (see Figure 3). Laboratory E. coli, excepting E. coli K-12, were intolerant to superoxide stress. All UC strains $(n=6)$ were intolerant to superoxide. Likewise, CRC-mucosa associated E. coli strains tested $(n=7)$ whilst able to tolerate growth at $\mathrm{pH} 5.0$ and oxidative stress induced by $\mathrm{H}_{2} \mathrm{O}_{2}$, were intolerant to superoxide stress, with the sole exception being HM229. No differences were seen in tolerance between E. coli from different sources with respect to acidic nor oxidative stress ( $p=0.3852$ and $p=0.1224$ respectively). One notable exception, ileal CD isolate LF11, was extremely sensitive to $\mathrm{H}_{2} \mathrm{O}_{2}$-induced oxidative stress (Figure 3).

2.3. Correlation of E. coli Tolerance to Methyl Viologen Induced Superoxide Stress with Ability to Replicate within Macrophages

A marked correlation was observed between replication of 48 E. coli strains $(n=16 \mathrm{CD}, n=7 \mathrm{CRC}$, $n=6 \mathrm{UC}, n=9 \mathrm{HC}, n=7 \mathrm{UTI}$ and $n=3$ laboratory strains) inside macrophages and their growth on LB agar under methyl viologen-induced superoxide stress ( $\rho=0.44$ [95\% CI, 0.47 to 0.86$]$, two-sided $p=0.0009$, Spearman's rank correlation coefficient) (Figure 4).

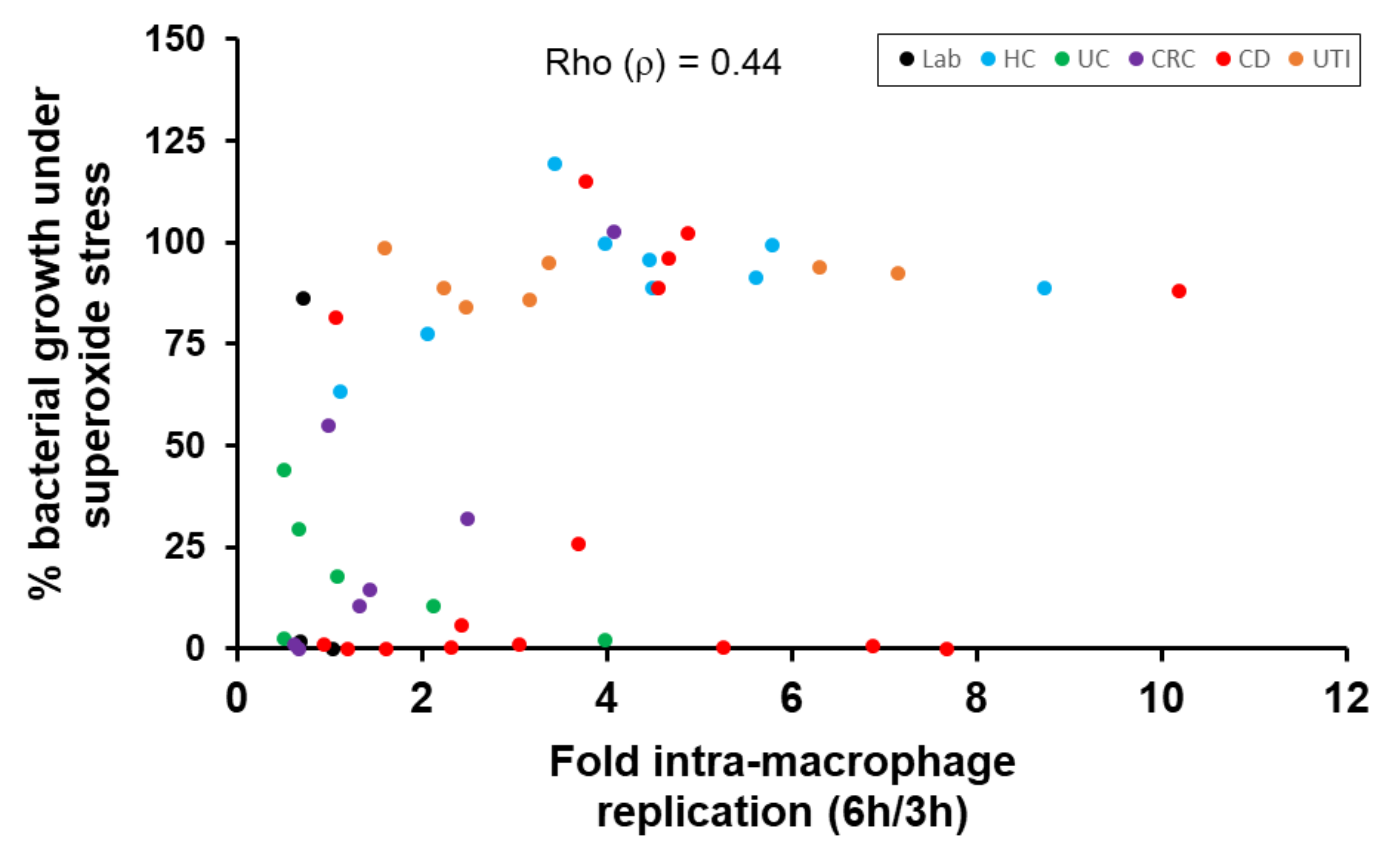

Figure 4. Correlation between growth of E. coli strains under superoxide stress conditions and their ability to replicate within macrophages. Spearman's rank correlation shows a monotonic direct relationship between growth of $48 \mathrm{E}$. coli; $n=16 \mathrm{CD}$ [Crohn's disease]-red circles, $n=7 \mathrm{CRC}$ [colorectal cancer] - purple, $n=6 \mathrm{UC}$ [ulcerative colitis [green], $n=9 \mathrm{HC}$ [healthy control individuals] - light blue, $n=7$ UTI [urinary tract infection] - orange circles and $n=3$ Lab [laboratory] strains-black) on solid media under superoxide stress (LB agar containing $1 \mathrm{mM}$ methyl viologen, $\mathrm{pH}$ 7.0) and their ability to survive and replicate within J774.A1 murine macrophages. Coefficient Rho $(\rho)=0.44$; two-sided $p=0.0009$.

\subsection{Crohn's Disease E. coli Isolates Are Able to Tolerate a Low-Nutrient, Acidic Environment}

Four CD mucosa-associated E. coli strains showing tolerance to all chemical stress conditions on solid agar (LF82, HM427, HM605 and HM615) were further examined for their ability to grow in nutrient-limiting conditions encountered within the macrophage phagolysosome. All four isolates showed tolerance over $8 \mathrm{~h}$ to low-nutrient M9 minimal culture medium both at $\mathrm{pH} 7.0$ and under acidic conditions, at pH 4.5 (see Figure 5). Laboratory E. coli strains K-12, EPI300 and XL-1Blue, which show little or no replication within murine macrophages, were able to grow in minimal M9 medium at 
$\mathrm{pH} 7.0$ but not at $\mathrm{pH}$ 4.5. No bacteria studied were able to grow in low-nutrient $\mathrm{M} 9$ minimal media at $\mathrm{pH} 4.0 ; N=3, n=3$.

A)

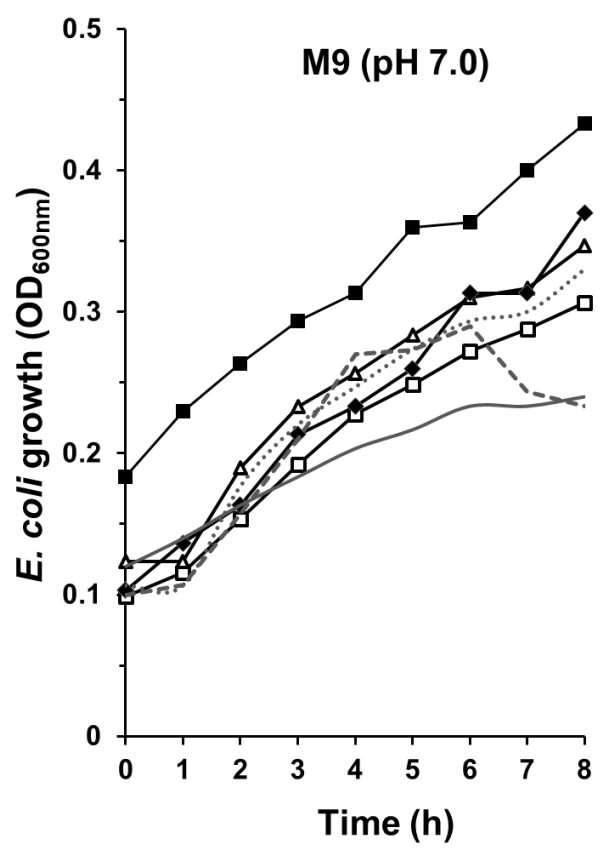

B)

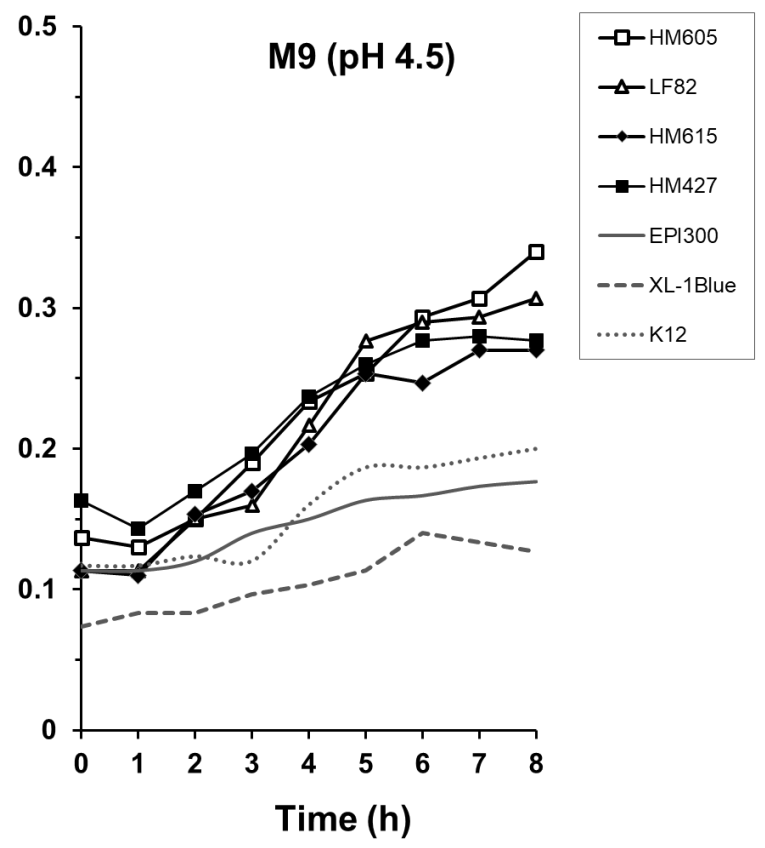

Figure 5. Crohn's disease mucosa-associated E. coli strains are able to grow within low-nutrient, acidic conditions characteristic of the macrophage phagolysosome environment. Comparison of CD mucosa-associated E. coli strains to non-intramacrophage replicating laboratory E. coli strains (EPI300, XL-1Blue and K-12) in low-nutrient culture medium (M9 minimal salts microbial growth medium supplemented with $0.1 \% \mathrm{w} / \mathrm{v}$ casamino acids, $100 \mathrm{mM}$ Bis-Tris, $0.16 \% \mathrm{v} / \mathrm{v}$ glycerol and $10 \mu \mathrm{M}$ magnesium chloride) at $\mathrm{pH} 7.0$ (A) and $\mathrm{pH} 4.5$ (B). All four CD E. coli strains showed tolerance over $8 \mathrm{~h}$ to low-nutrient $\mathrm{M} 9$ media, at $\mathrm{pH}$ 4.5. Laboratory E. coli strains were unable to grow well at $\mathrm{pH} 4.5$ in M9 minimal media. Lines represent means of triplicate experimental cultures, with $n=3$ replicates.

2.5. Crohn's Disease Mucosal E. coli HM605 and LF82 Replicate inside C57BL/6 Murine Bone Marrow-Derived Macrophages (BMDM), but Are Unable to Survive within Nfкb1-Deficient BMDM

It has been suggested that CD mucosal adherent, invasive E. coli (AIEC) strains can regulate the classical NF- $\mathrm{kB}$ signalling pathway to support their survival and persistence within the macrophage phagolysosome, including the prototype CD ileal-mucosa-associated AIEC strain LF82 [31]. We therefore selected this strain and another CD colonic-mucosa-associated AIEC, HM605, and examined for their ability to replicate within wild-type versus $N f \kappa b 1$-deficient bone marrow-derived macrophages (BMDM). Intra-phagolysosome survival and replication of both CD mucosa-associated E. coli strains within wild-type C57BL/6 mouse BMDM at $6 \mathrm{~h}$ post-infection was $>4$-fold above that seen at $3 \mathrm{~h}$ post-infection (LF82; $4.00 \pm$ 0.75-fold; HM605, $4.47 \pm 1.00$-fold [mean \pm SD]). However, both strains were unable to survive inside BMDM derived from $N f \kappa b 1^{--}$mice $(0.47 \pm 0.19$-fold and $0.56 \pm 0.28$-fold, respectively, for HM605 and LF82 (both $p<0.001$ compared to replication within C57BL/6 BMDM, unpaired $t$-test); see Figure 6. Phagocytosis of $E$. coli was not significantly different at $3 \mathrm{~h}$ in Nfkb1-deficient versus C57Bl/6 BMDMs (HM605, $41750 \pm 16645$ vs. $64500 \pm 10240 ;$ LF82, $27500 \pm 5928$ vs. $23500 \pm 5260$ [mean $\mathrm{cfu} \pm \mathrm{SD}]$. 


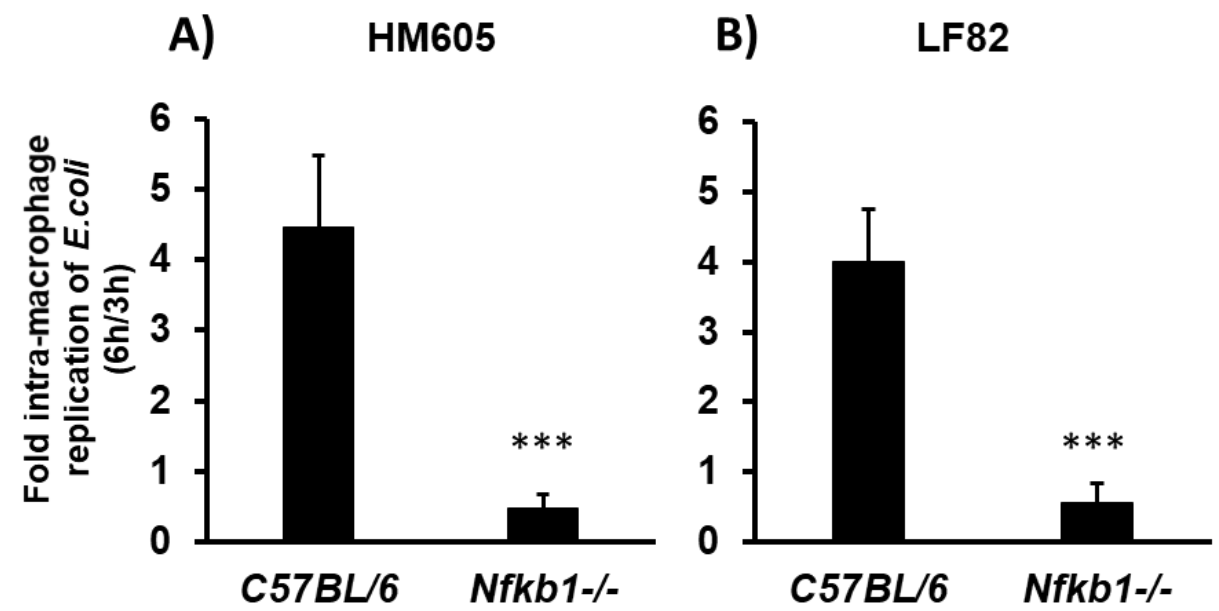

Figure 6. CD mucosa-associated E. coli are unable to survive within $N f \kappa b 1$-deficient murine bone-marrow derived macrophages (BMDM). Intra-macrophage replication of paradigm CD adherent, invasive E. coli HM605 (A) and LF82 (B) was significantly reduced within $N f k b 1^{--}$BMDM compared with those from $\mathrm{C} 57 \mathrm{BL} / 6$ mice as determined by gentamicin protection assay. Data are expressed as relative fold change [mean $\pm \mathrm{SD}$ ] of recovered intra-macrophage bacteria $6 \mathrm{~h}$ post-infection compared to the number of viable colony-forming units (cfu) obtained immediately after a 1-h gentamicin treatment step (i.e., $3 \mathrm{~h}$ post-infection). Data obtained from differentiated BMDMs obtained from bone progenitor cells from four C57BL/6 mice (two male, two female); and four $\mathrm{Nf}_{k} b 1^{--}$transgenic mice (one male, three female). Significant differences compared to C57BL/6 BMDMs ${ }^{* * *} p<0.001$, unpaired t-test.

2.6. Macrophage Pre-Incubation with the Corticosteroid Hydrocortisone Inhibits Intra-Macrophage Replication of a Crohn's Disease Mucosa-Associated E. coli

Pre-incubation of macrophages with hydrocortisone causes a dose-dependent decrease in survival of intra-macrophage CD colonic mucosa-associated E. coli HM605 in J774A.1 murine macrophages, with maximal effect, $70.49 \pm 12.11 \%$ (mean \pm SEM) inhibition, seen at $0.6 \mu \mathrm{M}(p<0.01$, Kruskal-Wallis ANOVA; $N=4$ experiments, $n=12$ replicates); Figure 7 . Preliminary experiments showed that the $24 \mathrm{~h}$ pre-incubation with hydrocortisone, at highest concentration tested $(6 \mu \mathrm{M})$, had no significant effects on J774-A1 macrophage cell viability (untreated control $3.27 \pm 0.86$ versus hydrocortisone $2.56 \pm$ 0.60 [mean \pm SEM cells $\left.x 10^{5} ; N=3, n=12\right]$ ) with no significant release of adenylate kinase to culture medium (untreated control 23,700 \pm 7510 versus hydrocortisone 20,100 \pm 6660 [mean luminescence units \pm SEM; $N=2, n=6]$ ). Hydrocortisone, at $6 \mu \mathrm{M}$, also had no direct effect on E. coli growth in culture medium for $6 \mathrm{~h}$ in the absence of macrophages, as assessed by enumeration of bacteria cfu following overnight growth on LB agar (Expt 1, control $1.64 \pm 0.06$ versus hydrocortisone $2.47 \pm 0.11$; Expt 2, control $3.91 \pm 0.12$ versus hydrocortisone $5.97 \pm 0.69$ [mean cfu x10 \pm SEM; both $n=6$ ]). 


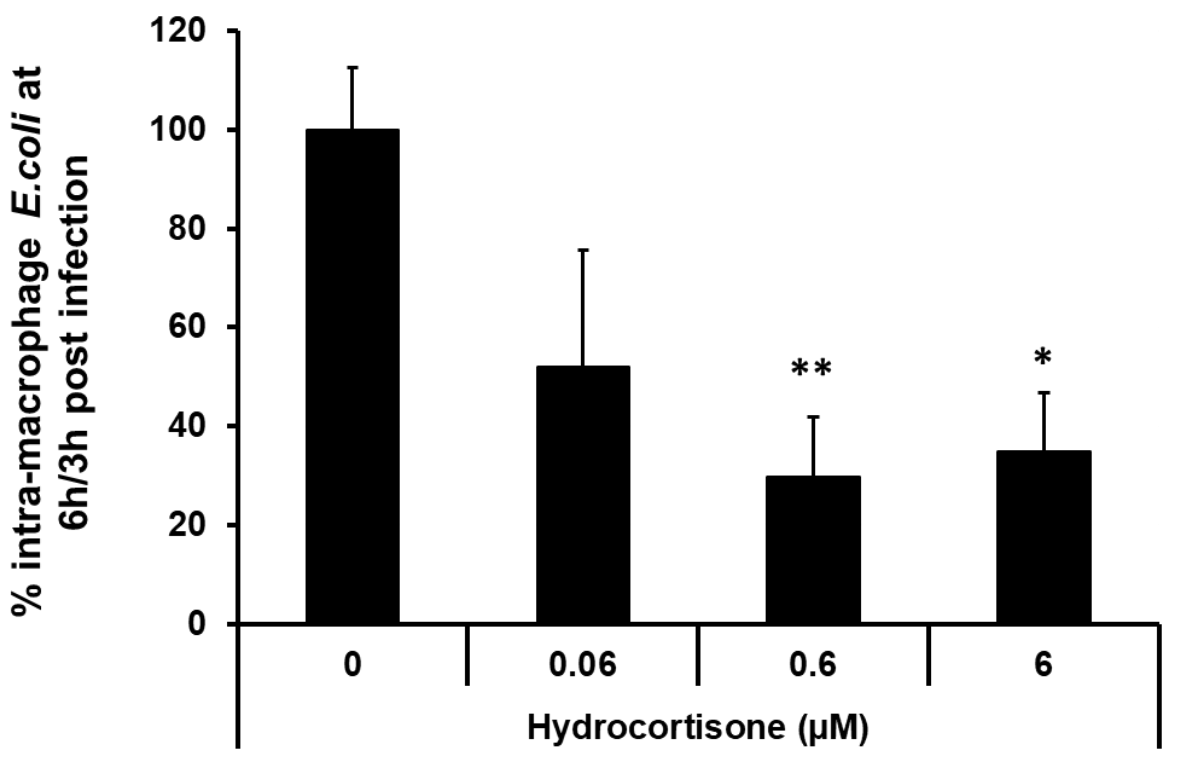

Figure 7. The effect of hydrocortisone on survival and replication of CD mucosa-associated E. coli HM605 within macrophages. J774A.1 murine macrophages were pre-treated with hydrocortisone for $24 \mathrm{~h}$ prior to inoculation with intra-macrophage replicating CD colonic mucosa-associated E.coli HM605. Data are expressed as mean \% intra-macrophage bacteria ( \pm SEM) present at $6 \mathrm{~h} / 3 \mathrm{~h}$ post-infection, as assessed using a gentamicin protection assay. Significant differences compared to vehicle-treated macrophages, ${ }^{*} p<0.05$ and ${ }^{* *} p<0.01$; Kruskal-Wallis non-parametric ANOVA: $N=4, n=12$.

\section{Discussion}

The ability of CD mucosal E. coli to survive and replicate within the phagolysosome following engulfment by mucosal macrophages confirms previous findings by ourselves [13,14] and others [11,12]. Although colonic E. coli strains examined here from UC and CRC patients did not show significant intra-macrophage replication, this phenotype is not specific to CD mucosal strains. UTI-associated strains also appeared to possess this property, with good survival and replication seen in murine macrophages. This confirms previous findings that uropathogenic E. coli (UPEC) strains isolated from patients with UTI can survive and replicate within murine macrophages, as well as possessing the ability to replicate within urogenital epithelial cells $[39,40]$. We also observed that the ability of $E$. coli to replicate within macrophages correlated strongly with an ability to tolerate a superoxide stress environment, as induced by methyl viologen within a growth medium, potentially mimicking the conditions encountered by bacteria inside a macrophage phagolysosome. All UTI-associated E. coli strains, including some key UPEC (CP9, J96 and SJH2) tested in this study, were able to tolerate superoxide stress. Key adherent, invasive mucosal E. coli from CD patients, including LF82 and HM605, were also tolerant of superoxide stress, although this ability appears to be variable, with other $C D$ strains being intolerant. Of note, E. coli K-12, which was not observed to replicate within macrophages, was able to tolerate superoxide stress, and indeed tolerated all growth stress conditions tested here. This strain has previously been reported to tolerate reactive oxygen stress, growing well in LB broth containing $1.5 \mathrm{mM} \mathrm{H}_{2} \mathrm{O}_{2}$ over $24 \mathrm{~h}$ [41]; this may perhaps explain its ability to persist within murine J774-A1 macrophages and human peripheral blood monocyte-derived macrophages over $6 \mathrm{~h}$, but not replicate to any significant degree, as was seen for CD mucosa-associated E. coli strains [13,14].

Overall, our data showed a strong correlation of $E$. coli tolerance to methyl viologen induced superoxide stress at $\mathrm{pH} 7.0$ with the ability to replicate within macrophages. It was not possible to conduct successfully in vitro experiments to further mimic the phagolysosome environment, i.e., superoxide stress at low $\mathrm{pH}(\mathrm{pH} 5.0)$, as we found that at $\mathrm{pH}<6.0$, methyl viologen was not able to generate superoxide radicals effectively, as has also been previously described [42]. Thus, mimicking growth conditions with all elements of the phagolysosome environment to monitor CD E. coli survival 
and replication is challenging and may only be achievable in E. coli-infected macrophages in culture or in vivo with use of multiphoton microscopy and oxidative, nitrosative and $\mathrm{pH}$ sensitive molecular probes, and probes that could measure proteolytic enzyme activities too.

Tolerance of the acidic, nutrient-limiting environment inside intra-macrophage phagolysosome is important for the survival and replication of key enteric bacteria such as Salmonella spp. [43,44] and Mycobacterium spp. [45,46], and has also been suggested for the exemplar ileal CD mucosal E. coli strain, LF82 [2]. Here we have shown that all CD mucosa-associated E. coli tested (whether isolates were ileal, ileal colonic or colonic in location, disease site and/or activity) were able to grow at a low $\mathrm{pH}$. Key CD mucosa-associated strains shown to be adherent and invasive to epithelial cells, including LF82 and HM605, were also shown in this study to grow and survive in a nutrient-depleted (M9 minimal media) environment. This supports earlier data that intra-macrophage survival and replication of the paradigm ileal CD E. coli isolate LF82 was dependent on an acidic environment [47]. A number of key bacterial stress response proteins have been implicated to support survival and persistence of LF82 within macrophages, such as the bacterial chaperone and serine protease high temperature requirement A (HtrA) and the bacterial thiol:disulfide bond oxidoreductase DsbA [47,48]. However, genes encoding these two bacterial enzymes were seen to be ubiquitous in an extensive screen of 281 colonic mucosa-associated isolates, whether obtained from patients with CD, UC, CRC or non-inflamed control patients [38]. Overall, the ability to persist and replicate within the low-pH environment of the macrophage vacuoles, suggests that alkalinisation of the intra-phagolysosome would perhaps be a good approach to target and reduce CD E. coli survival within macrophages, and subsequently to attenuate mucosal inflammation. Hydroxychloroquine, a weak base with the ability to increase phagolysosome $\mathrm{pH}$, has been shown to improve intra-macrophage killing of bacteria with an intra-phagolysosome life-style, such as Coxiella burnetii, causing Q-fever [49] and Tropheryma whipplei, causing Whipple's disease $[50,51]$. We have recently shown that hydroxychloroquine, at concentrations achievable in vivo, reduces survival and replication of intra-macrophage CD mucosal E. coli [25]. Hydroxychloroquine also had marked synergistic effects with antibiotics that were seen to be effective against intracellular E. coli $[14,25]$. With this in mind, we are currently undertaking a trial of combination antibiotics and hydroxychloroquine (APRiCCOT—ClinicalTrials.gov Identifier: NCT01783106) [52]. Other approaches to enhance CD mucosa-associated E. coli intra-macrophage killing could include the use of vitamin D supplementation [25].

Macrophage function and clearance of bacterial infection is not altered by the absence of Nfkb1 p50 subunit in vivo [53]; however, here we have shown that exemplar CD mucosal E. coli strains LF82 and HM605 cannot survive within $N f \kappa b 1^{--}$BMDMs, suggesting that inhibiting classical NF- $\mathrm{KB}$ pathway signalling specifically within macrophages could be therapeutically useful [54]. NF- $\mathrm{KB}$ signalling involves actions of five family member protein subunits/protein subunit complexes, including NF-kB1, NF-kB2, RelA (p65), RelB and c-Rel, controlling DNA transcription and subsequent expression of pro-inflammatory cytokines (such as TNF) to play a pivotal role in regulating immune response to infection [54,55]. High levels of TNF secreted by J774.A1 macrophages harbouring CD mucosa-associated E. coli strains, such as LF82 and 13I, are thought to support intra-macrophage survival and replication [31,32], with exogenous addition of TNF shown also to increase intra-macrophage persistence of E. coli LF82 [32]. Survival of these particular CD E. coli strains within murine macrophage phagolysosomes appears to involve initial suppression of acute NF- $\kappa B$ signal pathway activation within the early phase of infection [31], a common strategy used by other pathogenic bacteria to support intra-cellular survival [56,57]. Persistence of CD mucosal E. coli during the later phase of infection, however, likely results in a chronic activation of NF- $\mathrm{KB}$, correlating to increased release of TNF observed from infected macrophages [31].

Various anti-inflammatory and immunosuppressant agents, including glucocorticoids, strongly inhibit NF-KB activation by mechanisms that are not fully understood [53]. The evidence reported here, that pre-treatment of macrophages with hydrocortisone (at therapeutic doses), is perhaps surprising but has been reported previously for other corticosteroids [58,59], although there are also reports 
of a lack of impact of corticosteroids on bacterial killing by macrophages or neutrophils $[60,61]$. Although hydrocortisone exerts its effect mainly by acting on mucosal immune cells such as $\mathrm{T}$ cells, monocytes, macrophages and dendritic cells [62], we have shown that hydrocortisone also blocks NF- $\mathrm{kB}$ activated pro-inflammatory cytokine release from intestinal epithelial cells following infection with IBD mucosa-associated E. coli and is also beneficial in enhancing mucosal barrier function $[62,63]$. There is of course no doubt that corticosteroid therapy increases the risk of sepsis in many situations, including CD [64], and it is probable that other actions of corticosteroids including impairment of leucocyte chemotaxis contribute to this [65].

The studies reported here suggest that a macrophage-targeted inhibition of NF-KB activation could be a plausible therapeutic strategy for $\mathrm{CD}$. Despite considerable advances over the last decade or so, the role in $\mathrm{CD}$ of $E$. coli lacking conventional pathogenicity remains intriguing but unproven until it can be shown that therapeutic actions targeting the E. coli improve the condition.

\section{Materials and Methods}

\subsection{Murine Bone Marrow Isolation}

Ten- to 12-week-old wild-type C57BL/6 (Charles River, Margate, UK) and $\mathrm{Nfk}_{\mathrm{k}} \mathrm{1}^{-/}$mice, bred on the C57BL/6 genetic background [66], were maintained at the University of Liverpool's specific pathogen-free (SPF) Biomedical Services Unit under a 12:12 hour light/dark cycle and fed a standard pelleted chow diet. All mice were euthanized by cervical dislocation following UK Home Office Animals Scientific Procedures Act 1986 [67]. Bone marrow progenitor cells were obtained from femurs of four C57BL/6 mice ( $n=2$ male, $n=2$ female) and $4 \mathrm{Nf} \kappa b 1^{--}$transgenic mice ( $n=1$ male, $n=3$ female). Briefly, femurs from each mouse were flushed with culture medium and progenitor cells for each mouse were independently differentiated to macrophages with murine macrophage colony-stimulating factor (M-CSF) as previously described [68]. Maturation of BMDMs in culture was monitored by immunocytochemistry using F4/80/EMR1 primary antibody (CI-A3-1, Novus Europe, Abingdon, UK), with secondary anti-mouse Ig antibody/diaminobenzidine (DAB) substrate detection (Vector Labs, Peterborough, UK). No differences were observed in growth, differentiation (following $6 \mathrm{~d}$ treatment with M-CSF) and maturation (F4/80 positivity) of $\mathrm{Nf}_{\kappa} b 1^{-/}$BMDMs compared to C57Bl/6 BMDMs.

\subsection{Bacteria and Culture Conditions}

Bacteria stored at $-80{ }^{\circ} \mathrm{C}$ using the Protect ${ }^{\mathrm{TM}}$ bacteria preservation system (Fisher Scientific, Loughborough, UK) were sub-cultured overnight at $37^{\circ} \mathrm{C}$ on Luria-Bertani (LB) solid agar plates prior to use in experimental assays.

\subsubsection{E. coli Strains}

Mucosa-associated E. coli strains LF10, LF11, LF13, LF82 and LF86, were previously isolated from inflamed lesions of clinically active ileal CD patients [1,2,69]. E. coli strain 541-15A was previously isolated from patient with CD involving the ileum [4,35]. CD mucosa-associated strains HM95, HM96, HM104, HM413 and HM419 were isolated from non-inflamed colonic mucosa of patients in remission but with a history of active ileal inflammation. Isolate HM427 was obtained from the non-inflamed colon tissue of a CD patient who previously had ileo-colonic inflammation. HM154, HM580, HM605 and HM615 were isolated from inflamed colon biopsy tissue of CD patients [3].

\subsubsection{UC E. coli Strains}

Five strains, HM233, HM250, HM378, HM394 and HM457, were previously isolated from inflamed colon biopsy tissue of clinically active UC patients, with a further strain, HM464, having been isolated from the colonic mucosa of a UC patient in remission [3]. 


\subsubsection{CRC E. coli Strains}

Seven strains, HM44, HM229, HM230, HM244, HM312, HM358 and HM374, were previously isolated from the colonic mucosa of patients with CRC [3].

\subsubsection{Other E. coli Strains}

Additional reference $E$. coli strains were obtained from the STEC Centre (Department of Microbiology and Molecular Genetics, Michigan State University, East Lansing, MI, USA [70]), including ECOR40 and ECOR50 (isolated from patients with acute pyelonephritis), ECOR48 and ECOR64 (isolates from patients with acute cystitis). Uropathogenic E. coli (UPEC) included SJH2 and J96 (obtained from existing cryopreserved cultures within the Department of Clinical Infection, University of Liverpool, UK) and CP9 [71]. E. coli strains obtained from healthy individuals included ECOR1, ECOR35 and ECOR51 (STEC Centre). Other mucosally associated strains were isolated previously from the colon of otherwise healthy individuals with irritable bowel syndrome (HM484 and HM488), sporadic polyps (HM428, HM454 and HM456) or with haemorrhoids (HM463) [3]. E. coli K-12 (E. coli (Migula) Castellani and Chalmers ATCC ${ }^{\circledR} 10798$ ) was obtained from the American Type Culture Collection (LGC Standards, Middlesex, UK), E. coli XL-1Blue from Agilent Technologies (Santa Clara, CA, USA) and E. coli K-12 derivative EPI300-T1 from Epicentre (Madison, WI, USA). The latter strain was used as a negative control in the intra-macrophage replication assays.

\subsection{Bacteria Stress Tolerance Tests}

Stress tolerance tests were carried out as per [72]. Briefly, bacterial cultures were grown at $37^{\circ} \mathrm{C}$ in $\mathrm{LB}$ medium to an $\mathrm{OD}_{600 \mathrm{~nm}}$ 0.1, and diluted in 10-fold serial dilution steps in sterile physiological saline. Aliquots $(20 \mu \mathrm{L})$ from each dilution were spotted, in triplicate, to LB agar plates under the following stress conditions; LB agar pH 7.0 alone (standard conditions); LB agar containing $100 \mathrm{mM}$ 4-morpholine ethanesulfonic acid (MES) pH 5.0 (low $\mathrm{pH}$ ), with or without $1 \mathrm{mM}$ sodium nitrite (low $\mathrm{pH}$ and nitrosative stress); $1 \mathrm{mM}$ hydrogen peroxide, $\mathrm{pH} 7.0$ (oxidative stress); or $1 \mathrm{mM}$ methyl viologen, pH 7.0 (superoxide stress). Plates were incubated overnight at $37^{\circ} \mathrm{C}$. All chemicals were purchased from Sigma (Poole, UK).

\subsection{Bacteria Survival and Growth in Acidic Nutrient-poor M9 Medium}

At early exponential growth phase $\left(\mathrm{OD}_{600 \mathrm{~nm}}=0.1\right)$, bacteria were re-suspended in $\mathrm{M} 9$ minimal salts microbial growth medium (Life Technologies Ltd, Paisley, UK) supplemented with 0.1\% w/v Casamino Acids (MP Biomedicals, Loughborough, UK), 100 mM Bis-Tris (Sigma), 0.16\% v/v glycerol (Sigma) and $10 \mu \mathrm{M}$ magnesium chloride (Sigma), both at pH 7.0 and pH 4.5. OD of each bacterial suspension was measured on a spectrophotometer hourly up to $8 \mathrm{~h}$.

\subsection{Intra-Macrophage Replication Assays}

Murine macrophage-like cell line J774-A1, obtained from the European Collection of Animal Cell Culture (ECACC \#91051511; Porton Down, Salisbury, UK [73]), was maintained in RPMI 1640 medium (Sigma) supplemented with 10\% v/v foetal calf serum (Life Technologies, Paisley, Scotland), $100 \mathrm{U} / \mathrm{mL}$ penicillin (Sigma), $100 \mu \mathrm{g} / \mathrm{mL}$ streptomycin (Sigma), and 4mM L-glutamine (Sigma), within 75- $\mathrm{cm}^{2}$ tissue culture flasks (Appleton Woods Limited, Birmingham, UK). All macrophages (BMDM and J774.A1) were seeded onto 24-well tissue culture plates at a density of $1 \times 10^{5}$ cells per well. The ability of murine BMDM and J774A.1 macrophages to kill phagocytosed bacteria was assessed by a gentamicin protection assay previously described [14,25]. Briefly, following a $2 \mathrm{~h}$ incubation at $37^{\circ} \mathrm{C}$ to allow internalization of bacteria (multiplicity of infection, MOI 10), cell monolayers were washed thrice with sterile PBS to remove non-adherent bacteria and treated with fresh culture medium containing $20 \mu \mathrm{g} / \mathrm{mL}$ gentamicin for $1 \mathrm{~h}$ to kill extracellular bacteria. Following this, cells were washed with sterile PBS and replaced with a fresh medium containing $20 \mu \mathrm{g} / \mathrm{mL}$ gentamicin and incubated 
for a further $3 \mathrm{~h}$ at $37^{\circ} \mathrm{C}$. Data were expressed as relative fold change of recovered intra-macrophage bacteria at the end of the further 3-h incubation period ( $6 \mathrm{~h}$ post-infection) compared to the number of viable colony forming units ( $\mathrm{cfu}$ ) obtained immediately after the $1 \mathrm{~h}$ gentamicin treatment step (i.e., $3 \mathrm{~h}$ post-infection).

\subsection{Effect of Hydrocortisone Pre-Treatment of Macrophages on Intracellular Replication of E. coli}

J774-A1 murine macrophages were pre-incubated for $24 \mathrm{~h}$ in the presence of hydrocortisone $(0.06$ to $6 \mu \mathrm{M}$ ) and were then infected with CD E. coli HM605 (MOI 10) and killing/replication assessed as per [14]. Assessment of hydrocortisone treatment on J774-A1 macrophage cell viability was performed using the Toxilight assay (Lonza, Slough, UK) to assess for cytotoxicity, following release of adenylate kinase to culture medium. Hydrocortisone at concentrations tested was also assessed for any direct effect on $E$. coli growth in the absence of macrophages, assessed by enumeration of bacteria colony-forming units (CFU) following overnight growth on standard LB agar.

\subsection{Data Analysis}

Statistical comparisons of normally distributed datasets were performed by one-way analysis of variance (ANOVA) followed by Dunnett's post hoc test for pair-wise comparisons between treated and untreated/uninfected controls. Where there was evidence of non-normality or lack of homogeneity of datasets, the data were rank-transformed and non-parametric Kruskal-Wallis one-way ANOVA was used (StatsDirect version 2.6.2, Sale, UK). Differences were considered significant when $p<0.05$. Non-parametric correlation coefficient (Spearman's rank) analysis was used to assess for any association between \% bacterial growth in stress conditions and the ability to replicate inside murine macrophages. Visualisation of stress response data of $E$. coli isolates was performed using expression heat map freeware Heatmapper (University of Alberta, Edmonton, AB T6G 2E8, Canada) [74].

Author Contributions: Funding acquisition, A.T., B.J.C. and J.M.R.; conceptualization, B.J.C. and J.M.R.; resources, B.J.C., C.A.D. and D.M.P.; investigation, A.T., B.J.C. and P.K.; validation, A.T., B.J.C., C.A.D., D.M.P., J.M.R. and P.K.; data curation: A.T., P.K. and B.J.C.; supervision, B.J.C., C.A.D. and J.M.R.; project administration, B.J.C.; writing—original draft preparation, A.T., B.J.C. and J.M.R.; writing—review and editing, A.T., B.J.C., C.A.D., D.M.P., J.M.R. and P.K.. All authors approved the final manuscript.

Funding: A.T. was funded by the Ministry of Higher Education and Scientific Research, Libyan Embassy-Cultural Attaché, London; grant reference number, UM873-611-23962. P.K. was a clinical research fellow as part of a project award to J.M.R and B.J.C. (01CD1) within the NIHR Specialist Biomedical Research Centre in Microbial Disease based at the Royal Liverpool \& Broadgreen University Hospitals NHS Trust and University of Liverpool.

Acknowledgments: Ileal Crohn's disease LF designated E. coli strains were kindly provided by the late Professor Arlette Darfeuille-Michaud (Pathogénie Bactérienne Intestinale, Laboratoire de Bactériologie, Université d'Auvergne, Clermont-Ferrand, France). Ileal Crohn's disease E. coli isolate 515-15A was a kind gift from Professor Kenneth Simpson (College of Veterinary Medicine, Cornell University, Ithaca NY, USA). Uropathogenic E. coli CP9 was a kind gift from Dr Alison O'Brien (Department of Microbiology and Immunology, Uniformed Services University of the Health Sciences; Bethesda MD, USA). SJH2 and J96 were obtained from Professor Craig Winstanley (Department of Clinical Infection, Microbiology and Immunology, Institute of Global Health \& Infection, University of Liverpool, UK).

Conflicts of Interest: The authors declare no conflict of interest.

\section{References}

1. Darfeuille-Michaud, A.; Neut, C.; Barnich, N.; Lederman, E.; Di Martino, P.; Desreumaux, P.; Gambiez, L.; Joly, B.; Cortot, A.; Colombel, J.F. Presence of adherent Escherichia coli strains in ileal mucosa of patients with Crohn's disease. Gastroenterology 1998, 115, 1405-1413. [CrossRef]

2. Darfeuille-Michaud, A.; Boudeau, J.; Bulois, P.; Neut, C.; Glasser, A.L.; Barnich, N.; Bringer, M.A.; Swidsinski, A.; Beaugerie, L.; Colombel, J.F. High prevalence of adherent-invasive Escherichia coli associated with ileal mucosa in Crohn's disease. Gastroenterology 2004, 127, 412-421. [CrossRef] [PubMed] 
3. Martin, H.M.; Campbell, B.J.; Hart, C.A.; Mpofu, C.; Nayar, M.; Singh, R.; Englyst, H.; Williams, H.F.; Rhodes, J.M. Enhanced Escherichia coli adherence and invasion in Crohn's disease and colon cancer. Gastroenterology 2004, 127, 80-93. [CrossRef] [PubMed]

4. Kotlowski, R.; Bernstein, C.N.; Sepehri, S.; Krause, D.O. High prevalence of Escherichia coli belonging to the B2+D phylogenetic group in inflammatory bowel disease. Gut 2007, 56, 669-675. [CrossRef] [PubMed]

5. Baumgart, M.; Dogan, B.; Rishniw, M.; Weitzman, G.; Bosworth, B.; Yantiss, R.; Orsi, R.H.; Wiedmann, M.; McDonough, P.; Kim, S.G.; et al. Culture independent analysis of ileal mucosa reveals a selective increase in invasive Escherichia coli of novel phylogeny relative to depletion of Clostridiales in Crohn's disease involving the ileum. Isme J. 2007, 1, 403-418. [CrossRef] [PubMed]

6. Martinez-Medina, M.; Aldeguer, X.; Lopez-Siles, M.; González-Huix, F.; López-Oliu, C.; Dahbi, G.; Blanco, J.E.; Blanco, J.; Garcia-Gil, J.L.; Darfeuille-Michaud, A. Molecular diversity of Escherichia coli in the human gut: New ecological evidence supporting the role of adherent-invasive E. coli (AIEC) in Crohn's disease. Inflamm. Bowel Dis. 2009, 15, 872-882. [CrossRef] [PubMed]

7. Swidsinski, A.; Khilkin, M.; Kerjaschki, D.; Schreiber, S.; Ortner, M.; Weber, J.; Lochs, H. Association between intraepithelial Escherichia coli and colorectal cancer. Gastroenterology 1998, 115, 281-286. [CrossRef]

8. Sasaki, M.; Sitaraman, S.V.; Babbin, B.A.; Gerner-Smidt, P.; Ribot, E.M.; Garrett, N.; Alpern, J.A.; Akyildiz, A.; Theiss, A.L.; Nusrat, A.; et al. Invasive Escherichia coli are a feature of Crohn's disease. Lab Investig. 2007, 87, 1042-1054. [CrossRef]

9. Sepehri, S.; Khafipour, E.; Bernstein, C.N.; Coombes, B.K.; Pilar, A.V.; Karmali, M.; Ziebell, K.; Krause, D.O. Characterization of Escherichia coli isolated from gut biopsies of newly diagnosed patients with inflammatory bowel disease. Inflamm. Bowel Dis. 2011, 17, 1451-1463. [CrossRef]

10. Darfeuille-Michaud, A. Adherent-invasive Escherichia coli: A putative new E-coli pathotype associated with Crohn's disease. Int. J. Med. Microbiol. 2002, 292, 185-193. [CrossRef]

11. Glasser, A.L.; Boudeau, J.; Barnich, N.; Perruchot, M.H.; Colombel, J.F.; Darfeuille-Michaud, A. Adherent invasive Escherichia coli strains from patients with Crohn's disease survive and replicate within macrophages without inducing host cell death. Infect. Immun. 2001, 69, 5529-5537. [CrossRef] [PubMed]

12. Bringer, M.A.; Glasser, A.L.; Tung, C.H.; Meresse, S.; Darfeuille-Michaud, A. The Crohn's disease-associated adherent-invasive Escherichia coli strain LF82 replicates in mature phagolysosomes within J774 macrophages. Cell Microbiol. 2006, 8, 471-484. [CrossRef] [PubMed]

13. Mpofu, C.M.; Campbell, B.J.; Subramanian, S.; Marshall-Clarke, S.; Hart, C.A.; Cross, A.; Roberts, C.L.; McGoldrick, A.; Edwards, S.W.; Rhodes, J.M. Microbial mannan inhibits bacterial killing by macrophages: A possible pathogenic mechanism for Crohn's disease. Gastroenterology 2007, 133, 1487-1498. [CrossRef] [PubMed]

14. Subramanian, S.; Roberts, C.L.; Hart, C.A.; Martin, H.M.; Edwards, S.W.; Rhodes, J.M.; Campbell, B.J. Replication of colonic Crohn's disease mucosal Escherichia coli isolates within macrophages and their susceptibility to antibiotics. Antimicrob Agents Ch. 2008, 52, 427-434. [CrossRef] [PubMed]

15. Meconi, S.; Vercellone, A.; Levillain, F.; Payré, B.; Al Saati, T.; Capilla, F.; Desreumaux, P.; Darfeuille-Michaud, A.; Altare, F. Adherent-invasive Escherichia coli isolated from Crohn's disease patients induce granulomas in vitro. Cell Microbiol. 2007, 9, 1252-1261. [CrossRef] [PubMed]

16. Lissner, D.; Schumann, M.; Batra, A.; Kredel, L.I.; Kühl, A.A.; Erben, U.; May, C.; Schulzke, J.D.; Siegmund, B. Monocyte and M1 Macrophage-induced Barrier Defect Contributes to Chronic Intestinal Inflammation in IBD. Inflamm. Bowel Dis. 2015, 21, 1297-1305. [CrossRef]

17. Murray, P.J.; Wynn, T.A. Protective and pathogenic functions of macrophage subsets. Nat. Rev. Immunol. 2011, 11, 723-737. [CrossRef] [PubMed]

18. Shaw, K.A.; Cutler, D.J.; Okou, D.; Dodd, A.; Aronow, B.J.; Haberman, Y.; Stevens, C.; Walters, T.D.; Griffiths, A.; Baldassano, R.N.; et al. Genetic variants and pathways implicated in a pediatric inflammatory bowel disease cohort. Genes Immun. 2018, 20, 131. [CrossRef]

19. Turpin, W.; Goethel, A.; Bedrani, L.; Croitoru Mdcm, K. Determinants of IBD Heritability: Genes, Bugs, and More. Inflamm Bowel Dis. 2018, 24, 1133-1148. [CrossRef]

20. Smith, A.M.; Rahman, F.Z.; Hayee, B.H.; Graham, S.J.; Marks, D.J.; Sewell, G.W.; Palmer, C.D.; Wilde, J.; Foxwell, B.M.; Gloger, I.S.; et al. Disordered macrophage cytokine secretion underlies impaired acute inflammation and bacterial clearance in Crohn's disease. J. Exp. Med. 2009, 206, 1883-1897. [CrossRef]

21. Segal, A.W.; Loewi, G. Neutrophil dysfunction in Crohn's disease. Lancet 1976, 2, 219-221. [CrossRef] 
22. Segal, A.W. The role of neutrophils in the pathogenesis of Crohn's disease. Eur. J. Clin. Investig. 2018, 48 (Suppl. 2), e12983. [CrossRef]

23. Morain, C.O.; Segal, A.A.; Walker, D.; Levi, A.J. Abnormalities of neutrophil function do not cause the migration defect in Crohn's disease. Gut 1981, 22, 817-822. [CrossRef] [PubMed]

24. Rhodes, J.M.; Jewell, D.P. Motility of neutrophils and monocytes in Crohn's disease and ulcerative colitis. Gut 1983, 24, 73-77. [CrossRef] [PubMed]

25. Flanagan, P.K.; Chiewchengchol, D.; Wright, H.L.; Edwards, S.W.; Alswied, A.; Satsangi, J.; Subramanian, S.; Rhodes, J.M.; Campbell, B.J. Killing of Escherichia coli by Crohn's Disease Monocyte-derived Macrophages and Its Enhancement by Hydroxychloroquine and Vitamin D. Inflamm. Bowel Dis. 2015, 21, 1499-1510. [CrossRef] [PubMed]

26. Elliott, T.R.; Hudspith, B.N.; Rayment, N.B.; Prescott, N.J.; Petrovska, L.; Hermon-Taylor, J.; Brostoff, J.; Boussioutas, A.; Mathew, C.G.; Sanderson, J.D. Defective macrophage handling of Escherichia coli in Crohn's disease. J. Gastroenterol. Hepatol. 2015, 30, 1265-1274. [CrossRef]

27. Dale, D.C.; Boxer, L.; Liles, W.C. The phagocytes: Neutrophils and monocytes. Blood 2008, 112, $935-945$. [CrossRef] [PubMed]

28. Segal, A.W. How neutrophils kill microbes. Annu. Rev. Immunol. 2005, 23, 197-223. [CrossRef]

29. Forman, H.J.; Torres, M. Signaling by the respiratory burst in macrophages. Iubmb Life 2001, 51, 365-371.

30. Devasagayam, T.P.; Tilak, J.C.; Boloor, K.K.; Sane, K.S.; Ghaskadbi, S.S.; Lele, R.D. Free radicals and antioxidants in human health: Current status and future prospects. J. Assoc. Phys. India 2004, 52, 794-804.

31. Rahman, K.; Sasaki, M.; Nusrat, A.; Klapproth, J.M. Crohn's Disease-associated Escherichia coli Survive in Macrophages by Suppressing NFkappaB Signaling. Inflamm. Bowel Dis. 2014, 20, 1419-1425. [CrossRef] [PubMed]

32. Bringer, M.A.; Billard, E.; Glasser, A.L.; Colombel, J.F.; Darfeuille-Michaud, A. Replication of Crohn's disease-associated AIEC within macrophages is dependent on TNF-alpha secretion. Lab. Investig. 2012, 92, 411-419. [CrossRef] [PubMed]

33. O’brien, C.L.; Bringer, M.A.; Holt, K.E.; Gordon, D.M.; Dubois, A.L.; Barnich, N.; Darfeuille-Michaud, A.; Pavli, P. Comparative genomics of Crohn's disease-associated adherent-invasive Escherichia coli. Gut 2017, 66, 1382-1389. [CrossRef] [PubMed]

34. Chassaing, B.; Darfeuille-Michaud, A. The commensal microbiota and enteropathogens in the pathogenesis of inflammatory bowel diseases. Gastroenterology 2011, 140, 1720-1728. [CrossRef] [PubMed]

35. Dogan, B.; Suzuki, H.; Herlekar, D.; Sartor, R.B.; Campbell, B.J.; Roberts, C.L.; Stewart, K.; Scherl, E.J.; Araz, Y.; Bitar, P.P.; et al. Inflammation-associated adherent-invasive Escherichia coli are enriched in pathways for use of propanediol and iron and M-cell translocation. Inflamm. Bowel Dis. 2014, 20, 1919-1932. [CrossRef] [PubMed]

36. Camprubí-Font, C.; Ewers, C.; Lopez-Siles, M.; Martinez-Medina, M. Genetic and phenotypic features to screen for putative Adherent-Invasive Escherichia coli. Front Microbiol. 2019, 10, 108. [CrossRef] [PubMed]

37. Buc, E.; Dubois, D.; Sauvanet, P.; Raisch, J.; Delmas, J.; Darfeuille-Michaud, A.; Pezet, D.; Bonnet, R. High prevalence of mucosa-associated E. coli producing cyclomodulin and genotoxin in colon cancer. PLoS ONE 2013, 8, e56964. [CrossRef]

38. Prorok-Hamon, M.; Friswell, M.K.; Alswied, A.; Roberts, C.L.; Song, F.; Flanagan, P.K.; Knight, P.; Codling, C.; Marchesi, J.R.; Winstanley, C.; et al. Colonic mucosa-associated diffusely adherent afaC+Escherichia coli expressing lpfA and pks are increased in inflammatory bowel disease and colon cancer. Gut 2014, 63, 761-770. [CrossRef]

39. Bokil, N.J.; Totsika, M.; Carey, A.J.; Stacey, K.J.; Hancock, V.; Saunders, B.M.; Ravasi, T.; Ulett, G.C.; Schembri, M.A.; Sweet, M.J. Intramacrophage survival of uropathogenic Escherichia coli: Differences between diverse clinical isolates and between mouse and human macrophages. Immunobiology 2011, 216, 1164-1171. [CrossRef]

40. Mavromatis, C.; Bokil, N.J.; Totsika, M.; Kakkanat, A.; Schaale, K.; Cannistraci, C.V.; Ryu, T.; Beatson, S.A.; Ulett, G.C.; Schembri, M.A.; et al. The co-transcriptome of uropathogenic Escherichia coli-infected mouse macrophages reveals new insights into host-pathogen interactions. Cell Microbiol. 2015, 17, 730-746. [CrossRef]

41. Loui, C.; Chang, A.C.; Lu, S. Role of the ArcAB two-component system in the resistance of Escherichia coli to reactive oxygen stress. BMC Microbiol. 2009, 9, 183. [CrossRef] [PubMed] 
42. Van Dijk, C.; Veeger, C. The effects of $\mathrm{pH}$ and redox potential on the hydrogen production activity of the hydrogenase from Megasphaera elsdenii. Eur. J. Biochem. FEBS 1981, 114, 209-219. [CrossRef]

43. Rathman, M.; Sjaastad, M.D.; Falkow, S. Acidification of phagosomes containing Salmonella typhimurium in murine macrophages. Infect. Immun. 1996, 64, 2765-2773. [PubMed]

44. Fabrega, A.; Vila, J. Salmonella enterica serovar Typhimurium skills to succeed in the host: Virulence and regulation. Clin. Microbiol. Rev. 2013, 26, 308-341. [CrossRef] [PubMed]

45. Vandal, O.H.; Nathan, C.F.; Ehrt, S. Acid resistance in Mycobacterium tuberculosis. J. Bacteriol. 2009, 191, 4714-4721. [CrossRef]

46. Podinovskaia, M.; Lee, W.; Caldwell, S.; Russell, D.G. Infection of macrophages with Mycobacterium tuberculosis induces global modifications to phagosomal function. Cell Microbiol. 2013, 15, 843-859. [CrossRef] [PubMed]

47. Bringer, M.A.; Barnich, N.; Glasser, A.L.; Bardot, O.; Darfeuille-Michaud, A. HtrA stress protein is involved in intramacrophagic replication of adherent and invasive Escherichia coli strain LF82 isolated from a patient with Crohn's disease. Infect. Immun. 2005, 73, 712-721. [CrossRef]

48. Bringer, M.A.; Rolhion, N.; Glasser, A.L.; Darfeuille-Michaud, A. The oxidoreductase DsbA plays a key role in the ability of the Crohn's disease-associated adherent-invasive Escherichia coli strain LF82 to resist macrophage killing. J. Bacteriol. 2007, 189, 4860-4871. [CrossRef]

49. Maurin, M.; Benoliel, A.M.; Bongrand, P.; Raoult, D. Phagolysosomes of Coxiella burnetii-infected cell lines maintain an acidic $\mathrm{pH}$ during persistent infection. Infect. Immun. 1992, 60, 5013-5016.

50. Boulos, A.; Rolain, J.M.; Raoult, D. Antibiotic susceptibility of Tropheryma whipplei in MRC5 cells. Antimicrob Agents Chemother. 2004, 48, 747-752. [CrossRef]

51. Fenollar, F.; Puechal, X.; Raoult, D. Whipple's disease. N. Engl. J. Med. 2007, 356, 55-66. [CrossRef] [PubMed]

52. US National Library of Medicine-ClinicalTrials.gov. Antibiotics and Hydroxychloroquine in Crohn's (APRiCCOT). Available online: https://clinicaltrials.gov/ct2/show/NCT01783106 (accessed on 30 May 2019).

53. Mizgerd, J.P.; Lupa, M.M.; Kogan, M.S.; Warren, H.B.; Kobzik, L.; Topulos, G.P. Nuclear factor-kappaB p50 limits inflammation and prevents lung injury during Escherichia coli pneumonia. Am. J. Respir Crit. Care Med. 2003, 168, 810-817. [CrossRef] [PubMed]

54. Gupta, S.C.; Sundaram, C.; Reuter, S.; Aggarwal, B.B. Inhibiting NF-kappaB activation by small molecules as a therapeutic strategy. Biochim. Biophys. Acta 2010, 1799, 775-787. [CrossRef] [PubMed]

55. Merga, Y.J.; O’Hara, A.; Burkitt, M.D.; Duckworth, C.A.; Probert, C.S.; Campbell, B.J.; Pritchard, D.M. Importance of the alternative NF- $\mathrm{kB}$ activation pathway in inflammation-associated gastrointestinal carcinogenesis. Am. J. Physiol. Gastrointest Liver Physiol. 2016, 310, G1081-G1090. [CrossRef] [PubMed]

56. Krachler, A.M.; Woolery, A.R.; Orth, K. Manipulation of kinase signaling by bacterial pathogens. J. Cell Biol. 2011, 195, 1083-1092. [CrossRef] [PubMed]

57. Alto, N.M.; Orth, K. Subversion of Cell Signaling by Pathogens. Csh Perspect. Biol. 2012, 4, a006114. [CrossRef] [PubMed]

58. Meduri, G.U.; Kanangat, S.; Bronze, M.; Patterson, D.R.; Meduri, C.U.; Pak, C.; Tolley, E.A.; Schaberg, D.R. Effects of methylprednisolone on intracellular bacterial growth. Clin. Diagn Lab. Immunol. 2001, 8, 1156-1163. [CrossRef]

59. Van der Goes, A.; Hoekstra, K.; van den Berg, T.K.; Dijkstra, C.D. Dexamethasone promotes phagocytosis and bacterial killing by human monocytes/macrophages in vitro. J. Leukoc. Biol. 2000, 67, 801-807. [CrossRef]

60. Belchamber, K.B.; Thomas, C.M.; Dunne, A.E.; Barnes, P.J.; Donnelly, L.E. Comparison of fluticasone propionate and budesonide on COPD macrophage and neutrophil function. Int J. Chron Obs. Pulmon Dis. 2018, 13, 2883-2897. [CrossRef]

61. Losito, A.; Williams, D.G.; Cooke, G.; Harris, L. The effects on polymorphonuclear leucocyte function of prednisolone and azathioprine in vivo and prednisolone, azathioprine and 6-mercaptopurine in vitro. Clin. Exp. Immunol. 1978, 32, 423-428.

62. Subramanian, S.; Rhodes, J.M.; Hart, C.A.; Tam, B.; Roberts, C.L.; Smith, S.L.; Corkill, J.E.; Winstanley, C.; Virji, M.; Campbell, B.J. Characterization of epithelial IL-8 response to inflammatory bowel disease mucosal E. coli and its inhibition by mesalamine. Inflamm. Bowel Dis. 2008, 14, 162-175. [CrossRef] [PubMed]

63. Finnie, I.A.; Campbell, B.J.; Taylor, B.A.; Milton, J.D.; Sadek, S.K.; Yu, L.G.; Rhodes, J.M. Stimulation of colonic mucin synthesis by corticosteroids and nicotine. Clin. Sci. 1996, 91, 359-364. [CrossRef] [PubMed] 
64. Agrawal, A.; Durrani, S.; Leiper, K.; Ellis, A.; Morris, A.I.; Rhodes, J.M. Effect of systemic corticosteroid therapy on risk for intra-abdominal or pelvic abscess in non-operated Crohn's disease. Clin. Gastroenterol. Hepatol. 2005, 3, 1215-1220. [CrossRef]

65. Rhodes, J.M.; Bartholomew, T.C.; Jewell, D.P. Inhibition of leucocyte motility by drugs used in ulcerative colitis. Gut 1981, 22, 642-647. [CrossRef] [PubMed]

66. Sha, W.C.; Liou, H.C.; Tuomanen, E.I.; Baltimore, D. Targeted disruption of the p50 subunit of NF-kappa B leads to multifocal defects in immune responses. Cell 1995, 80, 321-330. [CrossRef]

67. Home Office. Animals (Scientific Procedures) Act 1986. Code of Practice for the Housing and Care of Animals Used in Scientific Procedures. Available online: https://assets.publishing.service.gov.uk/government/uploads/ system/uploads/attachment_data/file/516689/0107.pdf (accessed on 29 March 2019).

68. Minshawi, F.; White, M.R.H.; Muller, W.; Humphreys, N.; Jackson, D.; Campbell, B.J.; Adamson, A.; Papoutsopoulou, S. Human TNF-Luc reporter mouse: A new model to quantify inflammatory responses. Sci Rep. 2019, 9, 193. [CrossRef] [PubMed]

69. Masseret, E.; Boudeau, J.; Colombel, J.F.; Neut, C.; Desreumaux, P.; Joly, B.; Cortot, A.; Darfeuille-Michaud, A. Genetically related Escherichia coli strains associated with Crohn's disease. Gut 2001, 48, 320-325. [CrossRef] [PubMed]

70. ECOR group-E. coli Reference Collection of Natural Isolates. Available online: http://shigatox.net/new/ reference-strains/ecor.html (accessed on 23 February 2019).

71. Davis, J.M.; Carvalho, H.M.; Rasmussen, S.B.; O’Brien, A.D. Cytotoxic necrotizing factor type 1 delivered by outer membrane vesicles of uropathogenic Escherichia coli attenuates polymorphonuclear leukocyte antimicrobial activity and chemotaxis. Infect. Immun. 2006, 74, 4401-4408. [CrossRef]

72. Simonsen, K.T.; Nielsen, G.; Vester Bjerrum, J.; Kruse, T.; Kallipolitis, B.H.; Møller-Jensen, J. A Role for the RNA Chaperone Hfq in Controlling Adherent-Invasive Escherichia coli Colonization and Virulence. PLoS ONE 2011, 6, e16387. [CrossRef]

73. European Collection of Authenticated Cell Cultures (ECACC); Mouse BALB/c Monocyte Macrophage J774A.1 (ECACC 91051511). Available online: https://www.phe-culturecollections.org.uk/products/celllines/ generalcell/detail.jsp?refId=91051511\&collection=ecacc_gc (accessed on 30 May 2019).

74. Babicki, S.; Arndt, D.; Marcu, A.; Liang, Y.; Grant, J.R.; Maciejewski, A.; Wishart, D.S. Heatmapper: Web-enabled heat mapping for all. Nucleic Acids Res. 2016, 44, W147-W153. [CrossRef] 